\section{MtHAP2-1 is a key transcriptional regulator of symbiotic nodule development regulated by microRNA169 in Medicago truncatula}

\author{
Jean-Philippe Combier, ${ }^{1}$ Florian Frugier, ${ }^{2}$ \\ Françoise de Billy, ${ }^{1}$ Adnane Boualem, ${ }^{2}$ \\ Fikri El-Yahyaoui, ${ }^{1}$ Sandra Moreau, ${ }^{1}$ \\ Tatiana Vernié, ${ }^{1}$ Thomas Ott, ${ }^{1}$ Pascal Gamas, ${ }^{1}$ \\ Martin Crespi, ${ }^{2,4}$ and Andreas Niebel ${ }^{1,3}$

\begin{abstract}
${ }^{1}$ LIPM (Laboratoire des Interactions Plantes-Microorganismes) INRA-CNRS (Institut de National de la Recherche-Centre national de la recherche scientifique), 31326

Castanet-Tolosan, France; ${ }^{2}$ ISV (Institut des Sciences du Végétal), CNRS, 91198 Gif sur Yvette, France
\end{abstract}

In the model legume Medicago truncatula, we identified a new transcription factor of the CCAAT-binding family, MtHAP2-1, for which RNA interference (RNAi) and in situ hybridization experiments indicate a key role during nodule development, possibly by controlling nodule meristem function. We could also show that MtHAP2-1 is regulated by microRNA169, whose overexpression leads to the same nodule developmental block as MtHAP2-1 RNAi constructs. The complementary expression pattern of miR169 and MtHAP2-1 and the phenotype of miR169-resistant MtHAP2-1 nodules strongly suggest, in addition, that the miR169-mediated restriction of MtHAP2-1 expression to the nodule meristematic zone is essential for the differentiation of nodule cells.

Supplemental material is available at http://www.genesdev.org.

Received July 24, 2006; revised version accepted September 25,2006

The symbiotic association between nitrogen-fixing bacteria, collectively known as rhizobia, and plants belonging to the legume family, results in the formation of specialized root organs called nodules, inside which differentiated rhizobia reduce atmospheric nitrogen to ammonium for the benefit of the plant. In the model legume Medicago truncatula, nodules are indeterminate; they originate from root cortical cells that are stimulated by rhizobia to re-enter mitosis, which leads to the formation of a persistent meristem, allowing the subsequent development of the nodule (Geurts et al. 2005; Stacey et al. 2006). To obtain insights into the largely unknown mechanisms regulating root nodule development, transcriptome studies were performed in $M$. truncatula to

[Keywords: Nodulation; microRNA; transcription factor; symbiosis HAP2; Medicago]

Corresponding authors.

${ }^{3}$ E-MAIL aniebel@toulouse.inra.fr; FAX 33-5-61285061.

${ }^{4}$ E-MAIL martin.crespi@isv.cnrs-gif.fr; FAX 33-1-69823695.

Article is online at http://www.genesdev.org/cgi/doi/10.1101/gad.402806. search for transcription factors (TFs) implicated in early stages of nodulation. In this way we identified a gene, MtHAP2-1, whose expression is strongly up-regulated during nodule development (El Yahyaoui et al. 2004). This gene encodes an HAP2-type TF subunit, a component of the hetero-trimeric CCAAT-box-binding factor complex (CBF/NF-Y/HAP), comprising HAP2 (CBF-B, NF-YA), HAP3 (CBF-A, NF-YB), and HAP5 (CBF-C, NF$\mathrm{YC}$ ) subunits and characterized by its ability to bind the CCAAT motif present in many eukaryotic promoters (Maity and de Crombrugghe 1998). Interestingly, several genes coding CBF subunits have been shown to play central roles in development. This is the case for $C B F-B$ genes in the mouse (Bhattacharya et al. 2003), as well as for $L E A F Y$ COTYLEDON (LEC1) and LEAFY COTYLEDON1-LIKE (L1L), two HAP3 genes shown to be central regulators of embryogenesis in Arabidopsis thaliana (Lotan et al. 1998; Kwong et al. 2003; Lee et al. 2003). Similarly, HAP3 genes are involved in chloroplast biogenesis in rice (Miyoshi et al. 2003) and HAP5 in flowering-time control in Arabidopsis (Ben-Naim et al. 2006). In contrast to yeast and animals (where only one or two genes encode each CBF subunit), plants posses significantly more complex gene families. In $A$. thaliana there are 10
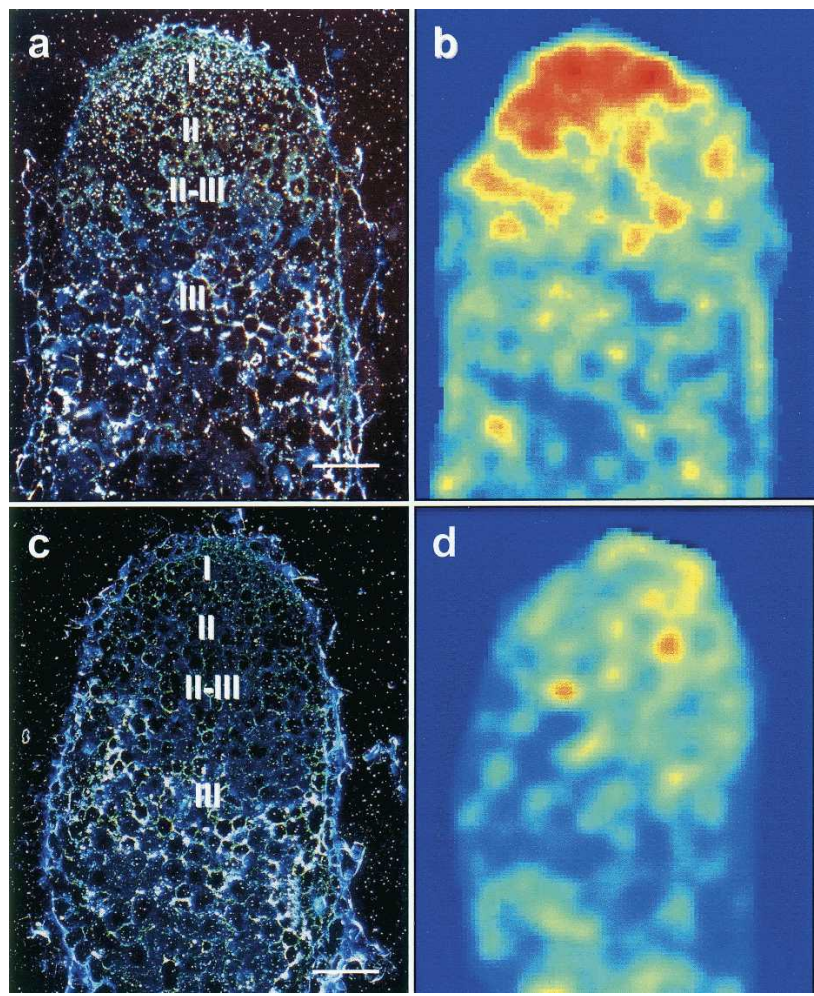

Figure 1. MtHAP2-1 expression is nodule specific and restricted to the meristematic-zone mRNA in situ hybridization of $M t H A P 2-1$ in nitrogen-fixing nodules. Sections are hybridized with an antisense $M t H A P 2-1$ probe $(a, b)$ or a control sense $M t H A P 2-1$ probe $(c, d)$. $a$ and $c$ are dark-field microscopy images, to visualize silver grains corresponding to $M t H A P 2-1$ mRNA localization. Nodule zones are indicated according to Vasse et al. (1990) (I, meristematic zone; II, infection zone; II-III, interzone; III, nitrogen fixation zone). $b$ and $d$ are color density maps performed using Image-Pro plus and Diatrack softwares. Bar, $100 \mu \mathrm{m}$. 
HAP2, $10 H A P 3$, and nine HAP5 genes (Gusmaroli et al. 2002). Functionally specialized gene family members controlling specific developmental pathways thus appear to exist in plants, possibly because of their ability to bind to other TFs such as MADS-box TFs (Masiero et al. 2002) or nuclear regulators such as CONSTANS (Ben-Naim et al. 2006).

\section{Results and Discussion}

We therefore undertook a detailed characterization of the MtHAP2-1 gene, which is strongly and specifically activated during symbiotic interactions (Supplementary Fig. 1). In situ hybridization showed that MtHAP2-1 mRNA is most abundant in cells of the nodule meristematic zone, less abundant in adjacent cells of the nodule infection zone, and not detected in all other nodule tissues (Fig. 1). The symbiotic role of MtHAP2-1 was then investigated by expressing MtHAP2-1 RNA interference (RNAi) constructs in transgenic $M$. truncatula roots. This resulted in a reduction of $M t H A P 2-1$ expression (Fig. 4b, below) sufficient to significantly alter nodule development. Nodulation was delayed and nodule growth arrested at $\sim 8-10 \mathrm{~d}$ post-inoculation (Fig. 2a,b). Inside the resulting spherical nodular structures, the absence of the clearly delimited zones found in wildtype nodules (I, meristem zone; II, Rhizobia infection zone; III, nitrogen-fixing zone; Fig. $2 \mathrm{e}, \mathrm{g}$ ) indicated an abnormal nodule developmental process. Growth arrest was often associated with the development of a closed endodermal layer surrounding the nodules (Fig. 2e). In addition, cells of the apical meristematic zone lost their typical polyhedral shape and accumulated numerous enlarged vacuoles (Fig. 2c,d). MtHAP2-1 RNAi nodules were also unable to fix nitrogen as shown by the reduced development of plants grown in the absence of mineral nitrogen (Fig. 2h). This phenotype was confirmed by electron microscopy observations showing that in the infection zone of mature MtHAP2-1-RNAi nodules, bacteria were not released from infection threads (Supplementary Fig. 2). On the few occasions for which release could be observed, the corresponding rhizobia were arrested in their development and never differentiated into nitrogenfixing type IV bacteroids (Vasse et al. 1990; data not shown). Taken together, these results suggest that MtHAP2-1 is a novel symbiosisspecific TF playing a key role during nodule development by controlling meristem persistence and probably also symbiotic bacterial release.

MicroRNAs (miRNA) are small 21-nucleotide (nt) RNAs that play important regulatory roles in plants and metazoans by targeting mRNAs either for cleavage or translation inhibition (Jones-Rhoades et al. 2006). miRNAs have generally been shown to target genes controlling development, many of them encoding TFs (Li and Zhang 2005; Jones-Rhoades et al. 2006). Since previous studies had suggested that HAP2 TFs are potential targets of miR169 in $A$. thaliana) (Jones-Rhoades and Bartel 2004), we searched for miR169 complementary sequences in the MtHAP2-1 gene, and found two such sequences in the $3^{\prime}$ untranslated region (UTR) (Fig. 3a). An in silico approach then identified a $M$. truncatula gene susceptible to encode a miR169 precursor, called MtmiR169- $a$, and secondary structure predictions revealed the capacity of $M t$ miR169- $a$ to form a stable stem-loop, as expected for a pre-miRNA (Fig. 3b). To investigate gene functionality we overexpressed the putative MtmiR169-a gene in transgenic $M$. truncatula roots under the control of a $35 \mathrm{~S}$
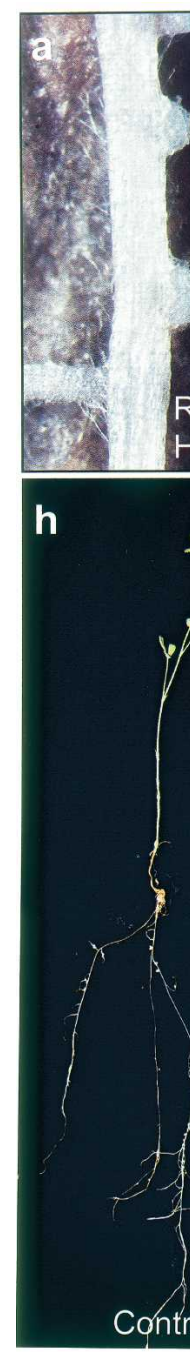

Figure 2. Altered nodulation phenotypes of MtHAP2-1 RNAi and 35S:MtmiR169-a roots. $(a, b)$ Nodule development on roots transformed with either an MtHAP2-1 RNAi construct $(a)$ or a control construct (empty vector) (b). Pictures were taken 46 d post-Rhizobium inoculation (d.p.i.). $(c, d)$ Electron microscopy images of the meristematic zone of $M t H A P 2-1$ RNAi $(c)$ and control $(d)$ nodules. (V) Vacuoles. Cells of the meristematic region of $M t H A P 2-1$ RNAi nodules already start to loose meristematic characteristics at 10 d.p.i. $(c)$, while they are still fully functional in control nodules at 27 d.p.i. $(d)$. Bar, $5 \mu \mathrm{m}$. $(e-g)$ Light microscopic images of longitudinal sections of 20-d-old nodules, using an overlay of two fluorescence images. Note the absence of normal nodule zonation and the abnormal closed endodermis (E) in MtHAP2-1 RNAi (e) and Mtmir169-a-overexpressing (f) nodules, compared with control (empty vector) $(g)$ nodules, indicating nodule developmental arrest. Bar, $100 \mathrm{um}$. (h) Growth of Rhizobium-inoculated plants after $40 \mathrm{~d}$ in the absence of mineral nitrogen reveals a deficient nitrogen fixation phenotype for MtHAP2-1 RNAi and 35S:Mtmir169- $a$ plants compared with control plants. 
a
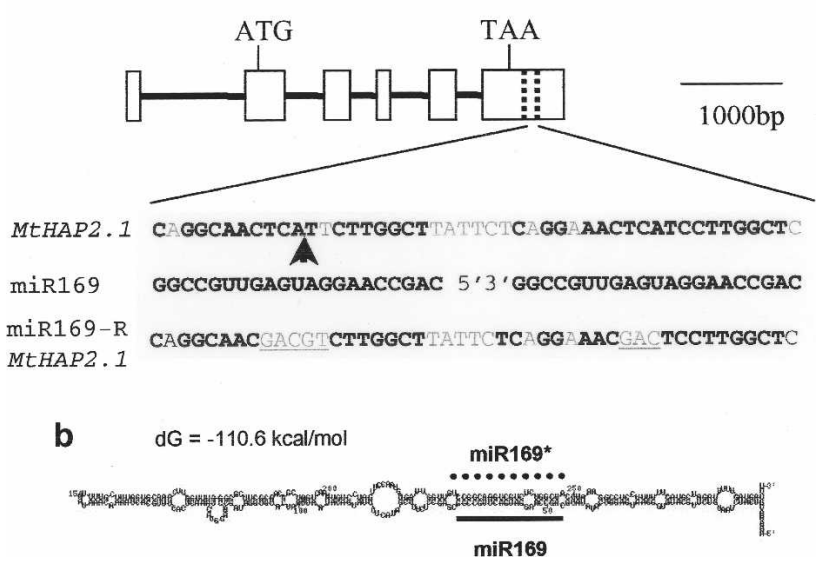

Figure 3. A miR169-a precursor induces cleavage of MtHAP2-1 mRNA. (a) Schematic representation of the MtHAP2-1 gene with intron (line)-exon (boxes) structure and position of the two putative miR169 recognition sites (dotted lines) in the 3' UTR of the gene. Alignment of miR169 with the two miR169 recognition sites in MtHAP2-1; conserved nucleotides are indicated in bold on the MtHAP2-1 sequence. Arrow shows predominant cleavage site revealed by $5^{\prime}$ RACE-PCR. Underlined nucleotides are those changed by site-directed mutagenesis in the miR169-resistant MtHAP2-1 mutant (miR169-R MtHAP2-1). (b) Most probable stem-loop structure of MtmiR169-a, indicating position of mature miR169 (line) and complementary miR169* (dotted line) sequences.

promoter. This led to an increased accumulation not only of the miR169 precursor (pre-miR169-a) (data not shown) but also of the mature miR169 (Fig. 4a), confirming that MtmiR169-a encodes microRNA 169. Evidence for miR169-mediated cleavage of MtHAP2-1 mRNA was then obtained by 5' RACE-PCR experiments, which showed that cleavage takes place predominantly at the first miR169 recognition site (Fig. 3a). Overexpression of MtmiR169- $a$ in transgenic roots led to a 3.5-fold reduction of MtHAP2-1 transcript levels (Fig. 4b), confirming unambiguously that miR169 has a major impact on $M t$ HAP2-1 expression. Importantly, the nodulation phenotype of these roots was remarkably similar to that observed with an MtHAP2-1 RNAi construct (Fig. 2e,f), indicating that miR169 regulation of MtHAP2-1 is functioning in planta, and that the control of the precise level of MtHAP2-1 mRNA is crucial for nodule development.

Real-time RT-PCR analysis showed that MtmiR169- $a$ expression is undetectable in roots, expressed in young developing nodules, and maximal in 10-d-old functional nodules (Fig. 4c). This contrasts strikingly with MtHAP2-1, whose expression is also nodule specific but maximal in young developing nodules, and then decreases as the nodule becomes functional (Fig. 4c). A pMtmiR169-a:GUS fusion revealed that this miRNA is present in adjacent tissues to those expressing MtHAP2-1 mRNA (Fig. 5a,b). Strikingly, MtmiR169-a transcript levels are highest in the infection zone (proximal to the meristem) (Fig. 5a,b), in which only lower levels of MtHAP2-1 are detected (Fig. 1). Conversely, MtmiR169-a promoter activity could not be detected in the meristematic zone in which most MtHAP2-1 mRNA is localized (Fig. 5b). These data are therefore consistent with a role of miR169 in restricting MtHAP2-1 transcripts to the nodule meristematic zone.

To evaluate the functional relevance of this miR169- mediated post-transcriptional regulation, a modified form of the MtHAP2-1 gene, mutated in both miR169 recognition sites (miR169-resistant MtHAP2-1) (Fig. 3a) was expressed under the control of its own promoter, in the presence or absence of the p35S:MtmiR169- $a$ construct. No difference was observed whether the p35S:MtmiR169-a construct was present or not (data not shown), suggesting that the mutated MtHAP2-1 construct is indeed miR169 resistant. Nodules that developed on these roots showed no alterations in tissue differentiation or in nodule zonation (Fig. 5c) and seemed functional according to plant development in the absence of mineral nitrogen (data not shown). The miR169resistant $M t H A P 2-1$ expressed under its own promoter can therefore restore nodulation, at least partly. This strongly suggests that the altered nodulation phenotype observed in p35S:MtmiR169- $a$ roots is mainly mediated by $M t H A P 2-1$ and probably not by other putative miR169 targets, although a minor contribution cannot be excluded. The growth, of microRNA169-resistant nodules was, however, significantly reduced compared with control nodules (Fig. 5c,d). This result shows that when MtHAP2-1 mRNA is not degraded by microRNA169 in the tissues surrounding the meristematic

a

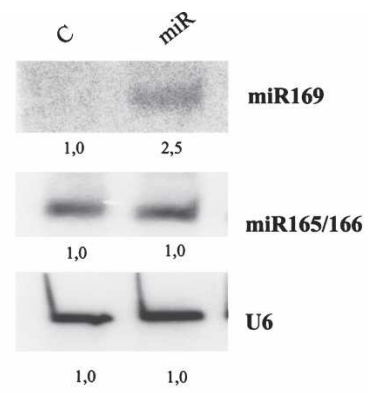

b

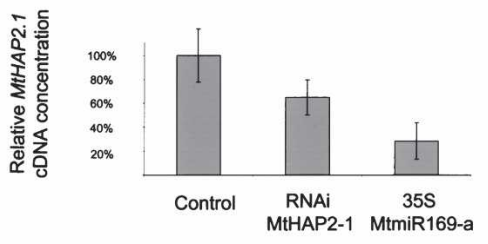

C

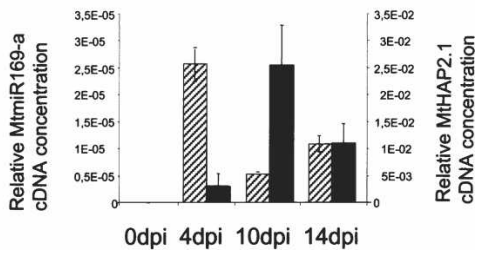

Figure 4. miR169 cleaves MtHAP2-1 in planta and MtHAP2-1 and the MtmiR169-a are oppositely regulated during nodulation. (a) Northern blot analysis of mature 21-bp miR169 expression in transgenic roots transformed with either empty vector control (C) or the 35S:MtmiR169-a constructs (miR). (b) Real-time RT-PCR analysis of MtHAP2-1 expression in MtHAP2-1 RNAi and 35S:MtmiR169-a compared with empty vector controls. Results are expressed as a percentage of the expression in control roots. (c) Real-time RT-PCR analysis of the expression pattern of MtmiR169-a (black boxes) and MtHAP2-1 (striped boxes) during nodule development. Relative expression levels are expressed in arbitrary units; the scale for MtmiR169- $a$ is on the left while the scale for MtHAP2-1 is on the right. 


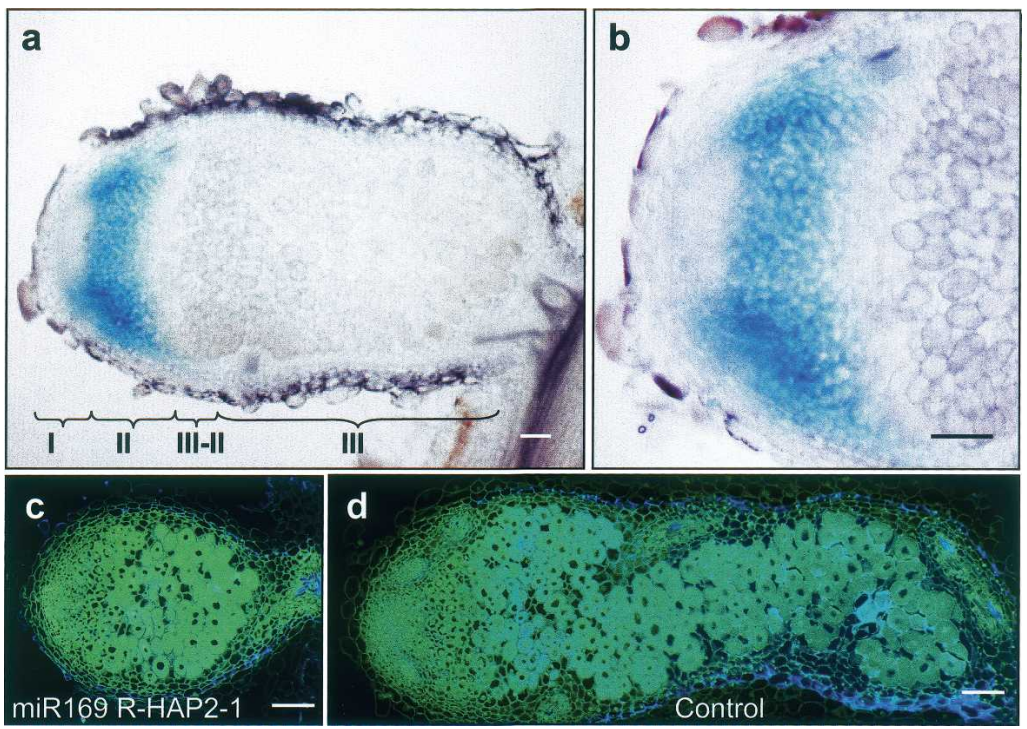

Figure 5. MtmiR169-a expression pattern in mature nodules and effects of a MtHAP2-1 miR169-resistant construct on nodule development. $(a, b)$ Expression analysis of MtmiR169-a in 14-d-old nodules revealed by promoter:GUS analysis. $b$ is a magnification of the distal part of the nodule depicted in $a$, showing the expression of MtmiR169- $a$ in the infection zone (II) and the absence of promoter activity in the meristematic region (I) of the nodule. Description of nodule zones is according to Vasse et al. (1990). Bar, $100 \mu \mathrm{m}$. (c-d) Images of longitudinal sections through 20-d-old nodules are an overlay of fluorescence images acquired with two different wavelengths, showing nodule development on transgenic roots expressing either a miR169-resistant MtHAP2-1 (miR169 R-HAP2-1) gene under the control of its own promoter (c), or an empty vector control (control) (d). Bar, $100 \mu \mathrm{m}$.

zone, nodule elongation is affected, suggesting an inhibitory role of $M t H A P 2-1$ on cell differentiation and/or an indirect role on meristematic activity. This is coherent with the central role in cell proliferation and early development that has been shown for members of the CCAAT-box-binding family in other systems. Conditional CBF-B mutants in mouse cells, for example, strongly affect cell division and embryonic development (Bhattacharya et al. 2003), and lec1 mutants are embryo lethal in A. thaliana (Lotan et al. 1998).

Our data show that MtHAP2-1, a novel symbiotically specialized CBF-B subunit, is essential for nodule meristematic persistence in $M$. truncatula, and that microRNA169 confers spatial and temporal accuracy to this developmental program. It is interesting to note that other TFs shown to specify shoot or root meristem development, such as CUC1-3 (Laufs et al. 2004), PHB, and PHV (Williams et al. 2005), or ICU4 (Ochando et al. 2006), are also the targets of microRNA mediated mRNA degradation. This additional level of regulation probably reflects the vital importance of meristems for plant development.

In conclusion, we propose that miR169-mediated regulation of $M t H A P 2-1$ expression leads to a critical spatial and temporal restriction of this TF to the nodule meristematic zone, thereby allowing correct tissue identity and the transition from meristematic to differentiated cells.

\section{Materials and methods}

Biological material

M. truncatula Gaertn cv. Jemalong genotype A17 was grown aeroponically as described in Journet et al. (2001), and inoculated with the Sino- rhizobium meliloti strain RCR2011 pXLGD4 (GMI 6526) (Ardourel et al. 1994) as described previously (El Yahyaoui et al. 2004).

Expression analysis

mRNA in situ hybridizations were performed as described in Gamas et al. (1998). Image processing and analysis were performed using the Image-Pro plus software (Media Cybernetics) and the Diatrack software (Semasopht). For real-time RT-PCR experiments, RNA was isolated using the SV total RNA extraction kit (Promega), and quality checked using a Bioanalyser (Agilent). Three micrograms of total RNA were reversetranscribed using the SuperScript II enzyme from Invitrogen. Real-time PCR was then performed on a LightCycler (Roche), using Syber-Green and specific primers. For MtHAP2-1, we used MtHAP2-1R and MtHAP2-1F (see Supplementary Table 1) while expression of the pre-MtmiR169-a was analyzed using miR169F and miR169R that amplify the stem-loop structure (249 base pairs [bp]) (Fig. 3b). Data were normalized using the EF1- $\alpha$ gene as described in El Yahyaoui et al. (2004). The specificity of primer pairs was confirmed by sequencing of PCR amplicons and the analysis of dissociation curves. Histochemical GUS staining was performed as described in Journet et al. (1994).

5' RACE-PCR experiment and Northern blot analysis of small RNAs

5' RACE-PCR was performed as described in Hirsch et al. (2006) using primers MtHAP2-1-3' (adapter), CBFrace-miR1 (inner), and CBF-race-miR2 (outer) (see Supplementary Table 1).

For Northern blots of small RNAs, extractions were performed using the TRIzol reagent (Invitrogen). Twenty micrograms of each RNA were subjected to electrophoresis on a $17 \%$ polyacrylamide denaturing gel and electroblotted onto Hybond $\mathrm{N}^{+}$ membranes (GE Healthcare) using a Miniprotean II system (Bio-Rad). Blots were hybridized with miR169, miR166, or U6 probes as described in Hirsch et al. (2006).

\section{Root transformation}

Root transformation using Agrobacterium rhizogenes was performed as described in Boisson-Dernier et al. (2005). Composite plants were subsequently transferred to growth pouches supplemented with nitrogen-deprived medium as in Gallusci et al. (1991) and inoculated with S. meliloti strain RCR2011 pXLGD4 (Ardourel et al. 1994).

Constructions and vectors

All primers are listed in Supplementary Table 1.

For all root transformation experiments, we used a Pgreen (http:// www.pgreen.ac.uk)-based vector with a modified polylinker, pPex (L. Sauviac, unpubl.).

For GUS fusion constructs, pPEX was modified by adding a GUS cassette from the pBS-GUS vector (Vernoud et al. 1999).

A 2.4-kb sequence upstream of the stem-loop structure of MtmiR169-a (Fig. 3b) was amplified using Pfx polymerase (Invitrogen) and primers MtmiR169-5' and Pre-miR169-3' and cloned into pPEX-GUS.

For RNAi experiments, the pPex vector was modified by introducing the intron from the pRNAi vector (Limpens et al. 2003) in addition to the cloning of the DSRED gene (under the control of the ubiquitin promoter) from the Predroot (Limpens et al. 2003) vector. A 298-bp region of the 3' UTR of the MtHAP2-1 gene showing no significant homology with other known MtHAP2 genes was amplified using primers CBF RNAi-5' and CBFRNAi-3' and cloned into the pPexRNAi vector.

For MtmiR169-a overexpression, a fragment located just outside of the stem-loop structure (Fig. 3b) was amplified with Pfx polymerase (Invitrogen) using miR169-5' and miR169-3' primers, and subsequently cloned into pPex.

For the miRNA-resistant version of MtHAP2-1, the gene including 2.3 $\mathrm{kb}$ of the upstream sequence was amplified with Pfx polymerase (Invitrogen) using the primers ProMtHAP2-1-5' and MtHAP2-1-3', and then cloned into pPex. Mutagenesis of the two miR169 recognition sites was 
performed by PCR amplification of this plasmid using Pfx polymerase (Invitrogen) and the following primers: first mutated miR169 recognition site (Fig. 3a): miR1muta-5' and miR1muta-3'; second miR169 recognition site (Fig. 3a): miR2muta-5' and miR2muta-3'. DpnI digestion was used to eliminate nonmutagenized plasmid prior to cloning.

Accession numbers: MtHAP2-1: MtC10582 (MENS database; http:// medicago.toulouse.inra.fr/Mt/EST) and TC95981(TIGR database; http:// www.tigr.org/tigr-scripts/tgi/T_index.cgi? species=medicago).

Pre-MtmiR169-a: BAC AC148485.10 (NCBI databases; http://www. ncbi.nlm.nih.gov/entrez/query.fcgi? $\mathrm{db}=$ PubMed).

\section{Acknowledgments}

We thank Laurent Sauviac (LIPM) for his kind gift of the pPex vector, René Geurts for his kind gift of the pRNAi and pRedroot vectors, Ton Timmers (LIPM) for fruitful discussions and advice concerning microscopy and imaging techniques, and Jean Marie Prosperi (INRA, Montpellier) for kindly providing seed stocks of $M$. truncatula A17. In addition, we are particularly grateful to David Barker, Jean Dénarié, Giles Oldroyd, and Hervé Vaucheret for critical reading of the manuscript. We thank Sakari Kaupinen (Exiqon, Denmark) for the kind gift of locked nucleic acid-modified oligonucleotides for detection of miR169. This work was supported by the European Comunity FP6 RIBOREG Project (LSHG-CT2003503022) and FP6 Grain Legume Integrated Project (FP6-2002-FOOD$1-506223)$.

\section{References}

Ardourel, M., Demont, N., Debelle, F., Maillet, F., de Billy, F., Prome, J.C., Denarie, J., and Truchet, G. 1994. Rhizobium meliloti lipooligosaccharide nodulation factors: Different structural requirements for bacterial entry into target root hair cells and induction of plant symbiotic developmental responses. Plant Cell 6: 1357-1374.

Ben-Naim, O., Eshed, R., Parnis, A., Teper-Bamnolker, P., Shalit, A., Coupland, G., Samach, A., and Lifschitz, E. 2006. The CCAAT binding factor can mediate interactions between CONSTANS-like proteins and DNA. Plant J. 46: 462-476.

Bhattacharya, A., Deng, J.M., Zhang, Z., Behringer, R., de Crombrugghe, B., and Maity, S.N. 2003. The B subunit of the CCAAT box binding transcription factor complex (CBF/NF-Y) is essential for early mouse development and cell proliferation. Cancer Res. 63: 8167-8172.

Boisson-Dernier, A., Andriankaja, A., Chabaud, M., Niebel, A., Journet, E.P., Barker, D.G., and de Carvalho-Niebel, F. 2005. MtENOD11 gene activation during rhizobial infection and mycorrhizal arbuscule development requires a common AT-rich-containing regulatory sequence. Mol. Plant Microbe Interact. 18: 1269-1276.

El Yahyaoui, F., Kuster, H., Ben Amor, B., Hohnjec, N., Pühler, A., Becker, A., Gouzy, J., Vernié, T., Gough, C., Niebel, A., et al. 2004. Expression profiling in Medicago truncatula identifies more than 750 genes differentially expressed during nodulation, including many potential regulators of the symbiotic program. Plant Physiol. 136: 35593576.

Gallusci, P., Dedieu, A., Journet, E.P., Huguet, T., and Barker, D.G. 1991. Synchronous expression of leghaemoglobin genes in Medicago truncatula during nitrogen-fixing root nodule development and response to exogenously supplied nitrate. Plant Mol. Biol. 17: 335-349.

Gamas, P., de Billy, F., and Truchet, G. 1998. Symbiosis-specific expression of two Medicago truncatula nodulin genes, MtN1 and MtN13, encoding products homologous to plant defense proteins. Mol. Plant Microbe Interact. 11: 393-403.

Geurts, R., Fedorova, E., and Bisseling, T. 2005. Nod factor signaling genes and their function in the early stages of Rhizobium infection. Curr. Opin. Plant Biol. 8: 346-352.

Gusmaroli, G., Tonelli, C., and Mantovani, R. 2002. Regulation of novel members of the Arabidopsis thaliana CCAAT-binding nuclear factor Y subunits. Gene 283: 41-48.

Hirsch, J., Lefort, V., Vankersschaver, M., Boualem, A., Lucas, A., Thermes, C., d'Aubenton-Carafa, Y., and Crespi, M. 2006. Characterization of 43 non-protein-coding mRNA genes in Arabidopsis, including the MIR162a-derived transcripts. Plant Physiol. 140: 11921204.

Jones-Rhoades, M.W. and Bartel, D.P. 2004. Computational identification of plant microRNAs and their targets, including a stress-induced
miRNA. Mol. Cell 14: 787-799.

Jones-Rhoades, M.W., Bartel, D.P., and Bartel, B. 2006. MicroRNAs and their regulatory roles in plants. Annu. Rev. Plant Biol. 57: 19-53.

Journet, E.P., Pichon, M., Dedieu, A., de Billy, F., Truchet, G., and Barker, D.G. 1994. Rhizobium meliloti Nod factors elicit cell-specific transcription of the ENOD12 gene in transgenic alfalfa. Plant J. 6: 241249.

Journet, E.P., El-Gachtouli, N., Vernoud, V., de Billy, F., Pichon, M., Dedieu, A., Arnould, C., Morandi, D., Barker, D.G., and GianinazziPearson, V. 2001. Medicago truncatula ENOD11: A novel RPRP-encoding early nodulin gene expressed during mycorrhization in arbuscule-containing cells. Mol. Plant Microbe Interact. 14: 737-748.

Kwong, R.W., Bui, A.Q., Lee, H., Kwong, L.W., Fischer, R.L., Goldberg R.B., and Harada, J.J. 2003. LEAFY COTYLEDON1-LIKE defines a class of regulators essential for embryo development. Plant Cell 15: 5-18.

Laufs, P., Peaucelle, A., Morin, H., and Traas, J. 2004. MicroRNA regulation of the CUC genes is required for boundary size control in Arabidopsis meristems. Development 131: 4311-4322.

Lee, H., Fischer, R.L., Goldberg, R.B., and Harada, J.J. 2003. Arabidopsis LEAFY COTYLEDON1 represents a functionally specialized subunit of the CCAAT binding transcription factor. Proc. Natl. Acad. Sci. 100: 2152-2156.

Li, X. and Zhang, Y.Z. 2005. Computational detection of microRNAs targeting transcription factor genes in Arabidopsis thaliana. Comput. Biol. Chem. 29: 360-367.

Limpens, E., Franken, C., Smit, P., Willemse, J., Bisseling, T., and Geurts, R. 2003. LysM domain receptor kinases regulating rhizobial Nod factor-induced infection. Science 302: 630-633.

Lotan, T., Ohto, M., Yee, K.M., West, M.A., Lo, R., Kwong, R.W., Yamagishi, K., Fischer, R.L., Goldberg, R.B., and Harada, J.J. 1998. Arabidopsis LEAFY COTYLEDON1 is sufficient to induce embryo development in vegetative cells. Cell 93: 1195-1205.

Maity, S.N. and de Crombrugghe, B. 1998. Role of the CCAAT-binding protein CBF/NF-Y in transcription. Trends Biochem. Sci. 23: 174178.

Masiero, S., Imbriano, C., Ravasio, F., Favaro, R., Pelucchi, N., Gorla, M.S., Mantovani, R., Colombo, L., and Kater, M.M. 2002. Ternary complex formation between MADS-box transcription factors and the histone fold protein NF-YB. J. Biol. Chem. 277: 26429-26435.

Miyoshi, K., Ito, Y., Serizawa, A., and Kurata, N. 2003. OsHAP3 genes regulate chloroplast biogenesis in rice. Plant T. 36: 532-540.

Ochando, I., Jover-Gil, S., Ripoll, J.J., Candela, H., Vera, A., Ponce, M.R., Martinez-Laborda, A., and Micol, J.L. 2006. Mutations in the microRNA complementarity site of the INCURVATA4 gene perturb meristem function and adaxialize lateral organs in arabidopsis. Plant Physiol. 141: 607-619.

Stacey, G., Libault, M., Brechenmacher, L., Wan, J., and May, G.D. 2006. Genetics and functional genomics of legume nodulation. Curr. Opin. Plant Biol. 9: 110-121.

Vasse, J., de Billy, F., Camut, S., and Truchet, G. 1990. Correlation between ultrastructural differentiation of bacteroids and nitrogen fixation in alfalfa nodules. J. Bacteriol. 172: 4295-4306.

Vernoud, V., Journet, E.-P., and Barker, D. 1999. MtENOD20, a nod factor inducible molecular marker for root cortical cell activation. Mol. Plant Microbe Interact. 12: 604-614.

Williams, L., Grigg, S.P., Xie, M., Christensen, S., and Fletcher, J.C. 2005 Regulation of Arabidopsis shoot apical meristem and lateral organ formation by microRNA miR166g and its AtHD-ZIP target genes. Development 132: 3657-3668. 


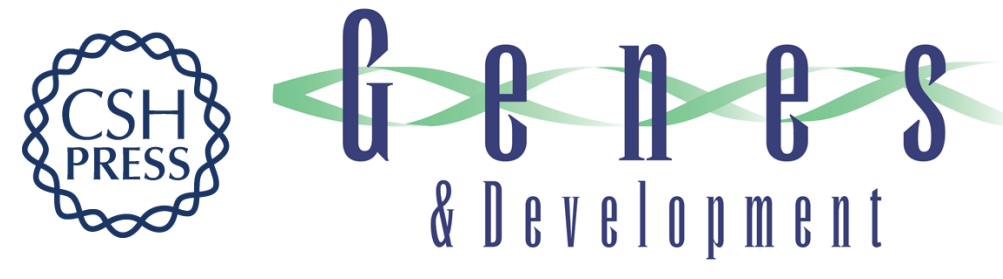

\section{MtHAP2-1 is a key transcriptional regulator of symbiotic nodule development regulated by microRNA169 in Medicago truncatula}

Jean-Philippe Combier, Florian Frugier, Françoise de Billy, et al.

Genes Dev. 2006, 20:

Access the most recent version at doi:10.1101/gad.402806

Supplemental http://genesdev.cshlp.org/content/suppl/2006/10/26/20.22.3084.DC1
Material

References This article cites 28 articles, 11 of which can be accessed free at:

http://genesdev.cshlp.org/content/20/22/3084.full.html\#ref-list-1

License

Email Alerting

Receive free email alerts when new articles cite this article - sign up in the box at the top

Service

right corner of the article or click here.

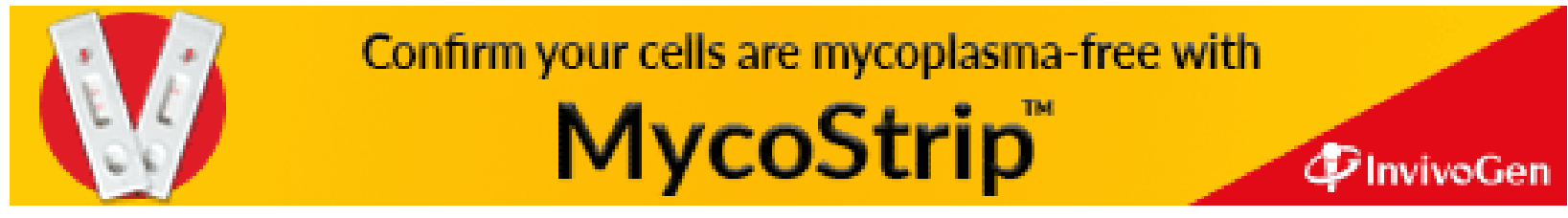

